\title{
The Biological Half-Life of Residual Drug in Eggs; Proposal of an Equation Predictable for the Half-Lives of Various Drugs
}

\author{
Naoto Furusawa ${ }^{1)}$, Takao Mukai ${ }^{2)}$ and Hitoshi OhORI ${ }^{2)}$ \\ ${ }^{1)}$ Faculty of Human Life Science, Osaka City University, \\ Sumiyoshi-ku, Osaka 558, Japan \\ ${ }^{2)}$ School of Veterinary Medicine and Animal Sciences, Kitasato University, \\ Towada, Aomori 034, Japan
}

The relationship between the biological half-lives of various drugs in a whole egg and the drug contents in egg yolk and albumen, which have been presented in many papers, was examined.

The regression analysis indicated a highly significant relationship $(\mathrm{P}<0.01)$ between the observed half-lives and the ratio of drug contents between egg yolk and albumen $(C$ $\mathrm{y} / \mathrm{a})$, and proposed was the following equation of the half-life (days) $=1.50 \cdot C_{\mathrm{y} / \mathrm{a}}{ }^{0.25}$. Where, $C_{\mathrm{y} / \mathrm{a}}$ is the drug content ratio in egg yolk to in albumen at the withdrawal.

The half-lives of drugs in a whole egg can be easily predicted as far as their contents in the yolk and albumen of the egg laid at the withdrawal initiation of drugs is known. (Jpn. Poult. sci., $33: 310-315,1996$ )

Key words : biological half-life, drug residue, egg yolk, albumen, whole egg

\section{Introduction}

In recent years, the use of various drugs in poultry farming has increased to prevent diseases of poultry. As a result, there is concern that residues of these drugs may be retained in eggs derived from treated poultry. To produce eggs free from drug residues, it is necessary to determine the biological half-life in a whole egg, which is now to be the most reliable pharmacokinetic parameter for the withdrawal time of drug after administration.

In our previous papers (Furusawa et al., 1994 ; Furusawa and Mukai, 1995 b), it was presented that biological half-lives of both sulphamonomethoxine (SMM) (the half-life $=0.9$ days) and sulphadimethoxine (SDM) (1.0 days) in a whole egg were much shorter than those of other drugs, such as decoquinate (DEC) (3.8 days) and nicarbazine (NCZ) (4.2 days) (YosHIDA, 1988).

Remarkably higher contents of the former 2 drugs (SMM and SDM) in albumen than in egg yolk (Furusawa et al., 1994 ; Furusawa and Mukal, $1995 \mathrm{a}$, b), and lower contents of the latter 2 drugs (DEC and NCZ) (NOSE et al., 1982 ; YoshiDA, 1988) in

Received Dec. 14, 1995

1) To whom correspondence should be addressed : Naoto Furusawa, Faculty of Human Life Science, Osaka City University, Sumiyoshi-ku, Osaka 558, Japan Tel 06-605-2883, Fax 06605-3086 
albumen than in egg yolk were also noticed. The high content in egg yolk than in albumen seemed to lead to prolong the half-life in a whole egg, and vice versa. The findings strongly suggest that the half-life in whole egg tends to be influenced by the ratio of drug contents in egg yolk and in albumen. We hypothesized that this ratio may be an important parameter for determining biological half-lives values of the drugs in a whole egg.

The purpose of this work was to evaluate the application of this ratio to various drugs, based on the data generated in our laboratory as well as other researchers.

\section{Materials and Methods}

\section{Drugs and their depletion data}

The data on the depletion of 13 drugs ( 4 antibiotics and 9 synthetic antibacterials) in whole egg and their contents (mg/kg : ppm) in egg yolk and albumen, which had been reported by us and other researchers, were utilized in this study (Table 1).

Data analysis

As biological half-lives in a whole egg for pyrimethamine (PYR) (NAGATA et al., 1992) and sulphamethoxazole (SMX) (OIKAwa et al., 1977) have not been reported, these values were calculated by using the depletion data shown in the respective papers according to the method described in our previous paper (FURUSAWA et al., 1994).

A linear regression analysis was carried out between natural logarithm $(l n)$ of the ratio of drug content in egg yolk to albumen at the withdrawal $\left(C_{y / a}\right)$ and $\ln$ of the observed biological half-life $\left(t_{1 / 2}\right)$ of the drug in a whole egg.

The computer programs used in analysis are described by FuRUSAWA et al. (1994).

\section{Results}

A significant linear relationship $(\mathrm{P}<0.01)$ between $\ln C_{\mathrm{y} / \mathrm{a}}$ and $\ln$ of the observed biological half-life ( $t_{1 / 2}$, days) of the drug in whole egg (Table 1$)$ was observed. This relationship could be described by Equation 1, which was then transformed into Equation 2.

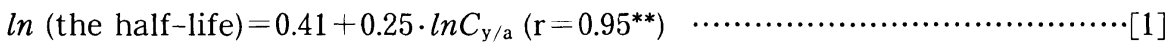

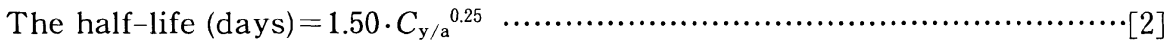

Using Equation 1, the biological half life in whole eggs for 13 drugs was predicted by individual $C_{y / a}$. Table 2 represents the predicted values termed as $T_{1 / 2}$ with their $95 \%$ confidence intervals, as well as the observed biological half-life $\left(t_{1 / 2}\right)$.

No statistically significant difference between the predicted values $\left(T_{1 / 2}\right)$ and those of the observed $\left(t_{1 / 2}\right)$ was demonstrated ( $P>0.05$, Table 2). Therefore, Equation 2 was shown to be very useful to determine the half-lives of 13 drugs in whole egg.

\section{Discussion}

To obtain eggs free from drug residues, an appropriate withdrawal time for the drugs must be established. Traditionally, biological half-lives of various drugs used in poultry have been determined by drawing the depletion profiles in eggs by measuring the drug contents at various days after the withdrawal. Simpler and more accurate 
Table 1. The experimental design of 13 drugs administrated orally to laying hens, the drug contents in egg yolk and albumen at the withdrawal, and the biological half-lives in whole egg

\begin{tabular}{|c|c|c|c|c|c|c|c|}
\hline \multirow[b]{2}{*}{ Drug } & \multicolumn{3}{|c|}{ Administration } & \multicolumn{2}{|c|}{ Drug contents ${ }^{a}$} & \multirow{2}{*}{$C_{y} / a^{b}$} & \multirow[b]{2}{*}{$t_{1 / 2}^{c}$} \\
\hline & Route & Dosage & $\begin{array}{c}\text { Duration } \\
\text { (days) }\end{array}$ & $\begin{array}{l}\text { Egg } \\
\text { yolk }\end{array}$ & Albumen & & \\
\hline \multicolumn{8}{|l|}{ Antibiotics: } \\
\hline Chlortetracycline (CTC) & Feed & $8,000 \mathrm{mg} / \mathrm{kg}$ diet & 7 & 0.27 & 0.23 & 1.2 & $1.6(1)^{\mathrm{d}}$ \\
\hline Oxytetracycline (OTC) & Feed & $4,000 \mathrm{mg} / \mathrm{kg}$ diet & 7 & 1.08 & 0.81 & 1.3 & $1.1(2)$ \\
\hline Spiramycin (SP) & Water & $400 \mathrm{mg} / l$ water & 5 & 1.41 & 0.67 & 2.1 & $2.4 \quad(3,4)$ \\
\hline Tylosin (TS) & Feed & $8,000 \mathrm{mg} / \mathrm{kg}$ diet & 7 & 5.20 & 5.20 & 1.0 & $1.3(5)$ \\
\hline \multicolumn{8}{|l|}{ Synthetic antibacterials: } \\
\hline Amprolium (AMP) & Feed & $100 \mathrm{mg} / \mathrm{kg}$ diet & 14 & 0.59 & 0.051 & 13.1 & $2.8(6)$ \\
\hline Decoquinate (DEC) & Feed & $40 \mathrm{mg} / \mathrm{kg}$ diet & 14 & 0.61 & 0.023 & 33.9 & $3.8 \quad(6,7)$ \\
\hline Dinitolmide (DTM) & Feed & $125 \mathrm{mg} / \mathrm{kg}$ diet & 14 & 1.57 & $0.15 \quad 1$ & 10.5 & $3.1(6,7)$ \\
\hline Nicarbazine (NCZ) & Feed & $200 \mathrm{mg} / \mathrm{kg}$ diet & 14 & 25.80 & 0.436 & 60.0 & $4.2(6,7)$ \\
\hline Pyrimethamine (PYR) & Feed & $1 \mathrm{mg} / \mathrm{kg}$ diet & 14 & 0.23 & 0.021 & 11.7 & $2.5^{\mathrm{e}}(8)$ \\
\hline Sulphadimidine (SDD) & Bolus $^{f}$ & $100 \mathrm{mg} / \mathrm{kg} \mathrm{BW}$ & 5 & 4.20 & 33.60 & 0.1 & $1.1(9)$ \\
\hline \multirow[t]{2}{*}{ Sulphamethoxazole (SMX) } & Feed & $2,000 \mathrm{mg} / \mathrm{kg}$ diet & 5 & 1.80 & 19.90 & 0.1 & $0.9^{\mathrm{e}}(10)$ \\
\hline & & $4,000 \mathrm{mg} / \mathrm{kg}$ diet & 5 & 2.90 & 39.00 & 0.1 & $0.9^{\mathrm{e}}(10)$ \\
\hline Sulphamonomethoxine (SMM) & Feed & $400 \mathrm{mg} / \mathrm{kg}$ diet & 5 & 1.49 & 6.87 & 0.2 & 0.9 \\
\hline Sulphadimethoxine (SDM) & Feed & $400 \mathrm{mg} / \mathrm{kg} \operatorname{diet}$ & 5 & 1.70 & 4.62 & 0.3 & $1.0 \quad(12)$ \\
\hline
\end{tabular}

${ }^{a}$ Average drug content (ppm: $\mathrm{mg} / \mathrm{kg}$ ) of egg laid at the withdrawal.

${ }^{\mathrm{b}}$ The drug content ratio in egg yolk to in albumen.

${ }^{\mathrm{c}}$ The observed biological half-life (days) in whole egg which have been presented in elsewhere.

${ }^{d}$ References : 1, Yoshida et al., 1973c ; 2, Yoshida et al., 1973b ; 3, Roudaut and Moretain, 1990 ; 4, Yoshida et al., 1971; 5, Yoshida et al., 1973 a ; 6, Nose et al., 1982;7, Yoshida, 1988;8, Nagata et al., $1992 ; 9$, Geertsma et al., 1987;10, Oikawa et al., 1977;11, Furusawa and Mukai, 1995 b ; 12, Furusawa et al., 1994.

${ }^{\mathrm{e}}$ The values for PYR (NAGATA et al., 1992) and SMX (OiKAwA et al., 1977) were calculated by using the depletion data shown in the respective papers according to the method described in previous paper (FURUSAWA et al., 1994).

${ }^{\mathrm{f}}$ Administered in capsules as a single dosage daily.

methods are needed to replace these time consuming depletion trials. In the present study, we tried to introduce a "general equation (the biological half-life in whole egg)" which may be calculated only from the data of the drug contents in egg yolk and albumen at the day of drug withdrawal.

A typical depletion profile for SMM (Furusawa and Mukai, $1995 \mathrm{~b}$ ) in egg yolk, albumen and the whole egg is presented in Figure 1. Depletion profile of SMM in egg yolk differs from that in albumen. Drug contents in egg yolk decreased almost linearly with relatively slow depletion after the withdrawal, while those in albumen decreased exponentially with rapid depletion. Generally, a slow depletion pattern in egg yolk and a rapid depletion in albumen is observed. This concept (kinetic behavior) may come from the difference of the process forming the two components of eggs. In the case of 
Table 2. Comparison of the observed $\left(t_{1 / 2}{ }^{\mathrm{b}}\right)$ and predicted $\left(T_{1 / 2}{ }^{\mathrm{c}}\right)$ biological half-lives (days) of 13 drugs in whole egg

\begin{tabular}{ccc}
\hline Drug $^{\mathrm{a}}$ & $t_{1 / 2}$ & $T_{1 / 2}$ \\
\hline CTC & 1.6 & $1.6[1.0 \sim 2.3]^{\mathrm{d}}$ \\
OTC & 1.1 & $1.5[1.0 \sim 2.4]$ \\
SP & 2.4 & $1.8[1.2 \sim 2.8]$ \\
TS & 1.3 & $1.4[0.9 \sim 2.2]$ \\
AMP & 2.8 & $2.8[1.9 \sim 4.3]$ \\
DEC & 3.8 & $3.6[2.3 \sim 5.6]$ \\
DTM & 3.1 & $2.7[1.8 \sim 4.1]$ \\
NCZ & 4.2 & $4.2[2.6 \sim 6.5]$ \\
PYR & 2.5 & $2.7[1.8 \sim 4.2]$ \\
SDD & 1.1 & $0.9[0.5 \sim 1.3]$ \\
SMX & 0.9 & $0.9[0.5 \sim 1.3]$ \\
SMM & 0.9 & $1.0[0.7 \sim 1.5]$ \\
SDM & 1.0 & $1.1[0.7 \sim 1.7]$ \\
\hline
\end{tabular}

${ }^{\text {a }}$ For abbreviations see Table 1.

${ }^{\mathrm{b}}$ See Table 1.

${ }^{c}$ The biological half-life in whole egg predicted from $C_{y / a}$ using Equation 2 in text.

d $95 \%$ confidence interval.

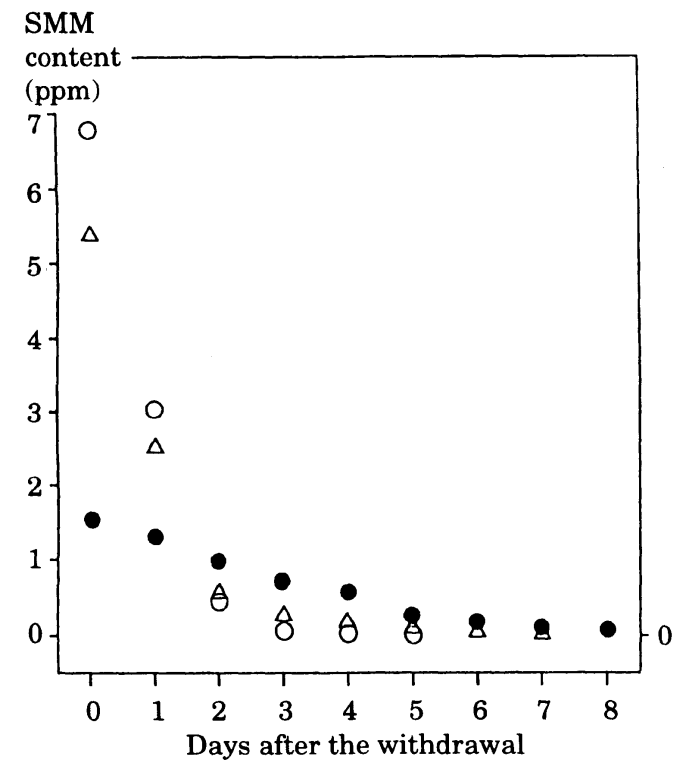

Fig. 1. Sulphamonomethoxine (SMM) contents (ppm: $\mathrm{mg} / \mathrm{kg}$ ) in egg yolk, albumen, and whole egg after the withdrawal.

Hens were fed the diet containing $400 \mathrm{ppm}$ of SMM for 5 days, thereafter, they were reared with the diet free from the drug during experimental period. SMM in egg yolk (solid circle), albumen (open circle) and whole egg (open triangle) were determined by the method described in the previous paper (FURUSAWA and MuKAI, 1995b). 
egg yolk formation, follicles grow linearly in size and weight in the ovary during the final $6 \mathrm{~d}$ of rapid growth stage (GILBERT, $1971 \mathrm{a}$ ), and ovulated into oviduct to develop intact component of eggs. Consequently, a linear increase in drug content in yolk during its grow th stage and a linear decrease after ovulation is expected. On the other hand, albumen is deposited only $3-10 \mathrm{~h}$ before shell formation (GILBERT, $1971 \mathrm{~b}$ ). As a result, the drug content may depend on that found in blood, where many drugs decrease exponentially as reported by Furusawa, et al. (1994). Thus, the depletion profile of drug in eggs depends largely on the physiology of egg formation. The egg has a separate kinetic compartment for the drug depletion and it is independent from hen's body. Hence, it can be said that the depletion kinetics in eggs may follow its unique rules (Furusawa and Mukai, 1995 b ; Geertsma et al., 1987).

As shown in Table 1, a large variation in the content of drugs in egg yolk and albumen are found with different drugs. This variation found in the yolk and albumen may depend mainly on the lipid-solubility or water-solubility of the drug (BLOM, 1975). The drugs having the property of lipid-solubility in nature such as NCZ and PYR are found much higher content in egg yolk than those in albumen. On the contrary, those having a water-solubility, such as sulphadimidine (SDD), SMX, SMM, and SDM are found higher content in albumen than those in egg yolk.

It is noteworthy that for lipid soluble drugs, longer the biological half-lives are found in whole eggs. Again, this phenomenon may be clearly elucidated by the fact that the higher contents of drug and slow depletion are demonstrated in egg yolk. The reversed phenomena are also found in the drugs classified into those having property of water-solubility (Table 1).

These facts led us to introduce the concept that the biological half-life in whole egg may depend on the ratio of the drug contents $\left(C_{\mathrm{y} / \mathrm{a}}\right)$ in the egg yolk to the albumen. As a result, we devised "general equation" (Equation 2) to predict biological half-lives of various drugs in whole egg using $C_{\mathrm{y} / \mathrm{a}}$ as the parameter. In the present study, the biological half-lives for the 13 drugs were calculated by using the "general equation". As seen in Table 2, the predicted values $\left(T_{1 / 2}\right)$ on all drugs examined statistically consisted with those of the observed biological half-lives $\left(t_{1 / 2}\right)(\mathrm{P}>0.05)$. Therefore, we concluded that Equation 2 can be a simple tool for describing the biological half-lives of various drugs in whole egg.

\section{References}

BLom, L. (1975) Plasma half-lives and the excretion into egg-white and -yolk of three sulphonamides and pyrimethamine after medication of laying hens. Acta Pharmacology et Toxicology, $37:$ 79-93.

Furusawa, N., Mukai, T. and Yoshida, M. (1994) Easiness of transfer of dietary sulfadimethoxine into eggs and its disappearance pattern from eggs. Japanese Poultry Science, 31:168-180.

Furusawa, N. and Mukai, T. (1995 a) Easiness of transfer of dietary sulfamonomethoxine into eggs. Japanese Poultry Science, $32: 26-33$.

Furusawa, N. and MukaI, T. (1995 b) Disappearance pattern of sulfamonomethoxine from eggs. Japanese Poultry Science, $32: 34-41$.

Furusawa, N. and MuKaI, T. $(1995 \mathrm{c})$ Transfer of dietary sulphamonomethoxine and sulphadimethoxine into various tissues of laying hens. British Poultry Science, 36 : 313-316. 
Geertsma, M.F., Nouws, J.F., Grondel, J.L., Aerts, M.M.L., Vree, T.B. and Kan, C.A. (1987) Residues of sulphadimidine and its metabolites in eggs following oral sulphadimidine medication of hens. Veterinary Quarterly, 9: 67-75.

GilberT, A.B. (1971 a) The Ovary, in : Bell, D.J. and Freeman, B.M. (Eds) Physiology and Biochemistry of the Domestic Fowl, pp. 1163-1208 (London, Academic Press).

Gilbert, A.B. (1971 b) Egg Albumen and its Formation, in : Bell, D.J. and Freeman, B.M. (Eds) Physiology and Biochemistry of the Domestic Fowl, pp. 1291-1330 (London Academic Press).

Nagata, T., SAeki, M., IidA, T., Kataoka, M. and ShiKano, S. (1992) Determination of pyrimethamine and sulphadimethoxine residues in eggs by high performance liquid chromatography. British Poultry Science, 33 : 953-961.

Nose, N., Hoshino, Y., Kikuchi, Y., Masaki, H., Horie, S. and Kawauchi, S. (1982) Residues of synthetic antibacterial feed additives in tissues and eggs of chickens. Journal of Food Hygiene Society of Japan, $23: 246-252$.

Oikawa, H., Nakamoto, K., Hirota, K. and KatagiRi, K. (1977) Clearance of sulfamethoxazole in eggs and tissues of chickens. Poultry Science, $56: 813-821$.

Roudaut, B and Moretain, J.P. (1990) Residues of macrolide antibiotics in eggs following medication of laying hens. British Poultry Science, 31:661-675.

Yoshida, M., Kuboto, D., Yonezawa, S., Nakamura, H., Azechi, H. and Terakado, N. (1971) Transfer of dietary spiramycin into eggs and its residue in the liver of laying hens. Japanese Poultry Science, $8: 103-110$.

Yoshida, M., Kubota, D., Yonezawa, S., Nakamura, H., Yamaoka, R. and Yoshimura, H. (1973a) Transfer of dietary tylosin into eggs and its residue in the liver of laying hens. Japanese Poultry Science, $10: 29-36$.

Yoshida, M., Kubota, D., Yonezawa, S., Nakamura, H., Yamaoka, R. and Yoshimura, H. (1973 b) Transfer of dietary oxytetracycline into eggs and its disappearance from eggs. Japanese Poultry Science, $10: 254-260$.

Yoshida, M., Kubota, D., Yonezawa, S., Nakamura, H., Yamaoka, R. and Yoshimura, H. (1973c) Transfer of dietary chlortetracycline into eggs and its disappearance from eggs and from the liver. Japanese Poultry Science, $10: 261-268$.

Yoshida, M. (1988) The residue and disappearance of chemicals, in : SAZAWA, H. and TANAKA, K. (Eds) Hand Book of Animal Hygiene, pp. 163-178 (Tokyo, Yoken-do, Japan Press). 